\title{
0 pós-abolição como problema histórico: balanços e perspectivas
}

\author{
Ana Maria Rios \\ $H$ ebe M aria M attos
}

\section{Introdução}

As visões da última geração de escravos brasileiros sobre seus planose destinos, após o 13 de maio, finalmente começam a emergir como um dos problemas históricos cruciais na historiografia brasileira sobre o período. A téa década de 1990, aproximadamente, apenasa marginalização dos libertos no mercado de trabalho pós-emancipação era enfatizada nas análises historiográficas. O súltimos cativos e seu destino após a abolição atraíam compaixão e simpatia, mas não pareciam apresentar maior potencial explicativo para a história do período. Com a abolição do cativeiro, os escravos pareciam ter saído das senzalas eda história, substituídos pela chegada em massa de imigrantes europeus.

Apesar disto, inúmeros trabalhos se dedicaram a estudar os projetos das elites a respeito dos libertos e da utilização dos chamados "nacionais livres" como mão-de-obra. D etalhes sobre diagnósticos e projetos de construção nacional, produzidos por el ites invariavelmente conservadoras, pautaram por muito tempo a discussão historiográfica sobre o período pósemancipação. ${ }^{1} \mathrm{M}$ el hor dizendo, o pós-abolição como questão específica se diluía na discussão sobre o que fazer com o "povo brasileiro" e a famosa "questão social".

$\mathrm{N}$ ão é nossa inten ção desqualificar a importância da análise dos projetos dominantes, que são vários e multifacetados e nos ajudam na compreensão dos projetos de Brasil em debate no cenário político a partir da perspectiva do fim da escravidão. N ossa intenção étentar demonstrar até queponto estes projetos estiveram informados por um conhecimento pragmático das elites agrárias sobre as expectativas dosúltimos libertos e deque 
maneira interagiram com as atitudes e opções adotadas por eles após o fim da escravidão.

\section{Alguns aspectos comparativos do pós-abolição}

D esde os anos 1970, quando preocupações macro-econômicas constituíam o principal aspecto analisado em termos comparativos nas sociedades pós-emancipação, muito se avançou nas discussões historiográficas sobre o tema. 0 acentuado declínio da produção açucareira daJ amaica após a abolição da escravidão, em contraste com continuidade sem quebras expressivas desta indústria em Trinidad, chamavam a atenção para as diferentes atitudes dos libertos quando da emancipação do trabal ho no C aribe B ritânico. As diferenças foram explicadas enfatizando a existência de uma fronteira agrária aberta na Jamaica, com espaços montanhosos einúteis para os canaviais, contraposta a uma fronteira agrícola fechada, como em Barbados, por exemplo. A existência ou não de uma fronteira agrícola aberta seria o elemento determinante para o entendimento da diferença do comportamento dos libertos nas duas ilhas, o que seria muitas vezes generalizado para outras regiões. Assim, nas condições defronteira aberta, oslibertos tenderiam a buscar a autonomia, a se retirarem do trabalho nas plantations e a criarem um estilo de vida camponês, vivendo próximo aos limites mínimos de subsistência, com efeitos desastrosos para a economia destas re giões. Ao contrario, onde a fronteira se encontrasse fechada, os libertos teriam que se submeter às condições de trabal ho propostas pel os empregadores, e os efeitos das mudanças na situação jurídica dos trabal hadores seriam minimizados. ${ }^{2}$

D a mesma forma, al guns trabal hos brasileiros das décadas de 1970 e 1980 enfatizaram um relativo paral elismo com esta situação. As dificuldades de reter na grande lavoura a chamada "mão-de-obra livrenacional" nas áreas escravistas do C entro-Sul, enfatizada pela dependência dessas áreas dos fluxos internacionais de trabalho imigrante e pela desarticulação da lavoura escravista dealimentos da região, substituída pela formação de um campesinato negro, foi considerada, por alguns autores, função da fronteira agrícola ainda aberta nestas áreas, em oposição ao fechamento dela nas antigas áreas açucareiras do nordeste. ${ }^{3}$ 
M as a vida não é assim tão simples. A "fronteira agrária" não é puramente um dado geográfico, e a experiência da mesma Jamaica, estudada mais de perto, mostrou que a utilização desta fronteira, para a formação das vilas camponesas, foi palco de encarniçada luta política, na qual o estado jogou toda sua força. Pesados impostos e taxas sobre os produtos camponeses e sobre a terra, leis coercitivas ao trabalho nas plantations, redefinições sobre direitos consuetudinários, estabelecidosno período escravista, eaté mesmo novos códigos de conduta e moral idade a serem aplicados aos libertos relativizaram bastante a proeminência da fronteira agrária aberta na Jamaica como fator determinante nos destinos daquela sociedade após a escravidão, enfatizando a dimensão de luta política dos libertos, desenvolvida em várias frentes, desde demandas no terreno jurídico atérevoltas abertas e violentas. ${ }^{4}$

Também neste aspecto, a historiografia brasileira seguiu percurso semelhante, passando a enfatizar os embates entre as expectativas dos libertos, que se definiam na forma de um "projeto camponês", eas condições políticas de acesso à terra e de garantia da sobrevivência em diferentes situações regionais. Especialmente, ficou empiricamente demonstrada que paralelamenteà formação de um campesinato negro, manteve-se a centralidade do liberto, enquanto força detrabal ho, nasfazendas das antigasáreas escravistas do sudeste, nas décadas que se seguiram imediatamente à escravidão. ${ }^{5}$

0 campo aberto para os estudos do pós-abolição passou assim a incluir variáveis epreocupações múltiplas. 0 papel do estado, dos ex-senhores, as condições em que eram exercidas as atividades que empregavam os escravos às vésperas do fim da escravidão, a existência ou não de possibilidades alternativas de recrutamento demão-de-obra (imigração) etc. Incluiu também a recontextual ização de conceitos como cidadania e liberdade e seus possíveis significados para os diversos atores sociais.

Robert Blackburn, historiador inglês, definiu o grande ciclo das revoluções atlânticas nas Américas, como uma "era das abolições", identificando na superação da escravidão africana e no acesso à cidadania entendida nos termos do novo ideário liberal, a principal transformação revolucionária do continente. ${ }^{6} \mathrm{D}$ e fato, até meados do século XVIII, a legitimidade da escravidão, mesmo que em contextos específicos, era compartilhada pelo pensamento cristão ocidental - católico ou protestante - e pelas muitas 
sociedades africanas envolvidas no tráfico. Foi a partir demeados do século XVIII que emergiram discursos abolicionistas no contexto da Ilustração européia, questionando progressivamentea legitimidadeda escravidão. D esde então, por diferentes caminhos, desde a emancipação escrava no H aiti, em 1794, atéa abolição definitiva da escravidão no Brasil, em 1888, a instituição escravista foi legalmente extinta em praticamente toda a AfroAmérica. N um contexto de emancipações políticas sucessivas em nomeda liberdade dos novos cidadãos, a questão dos direitos de cidadania dos libertos, o pensamento racial emergente nas novas nações em construção, bem como suas relações com os cânones do ideário liberal e com as variadas conjunturas históricas em queas diferentes sociedades escravistas viveram o processo da emancipação escrava ao longo de todo o século XIX, são variáveis que passaram a ser cada vez mais consideradas.

D a mesma forma, características específicas da escravidão e da população escrava passaram a ser analisadas para apreender aquilo que se tornou um diferencial marcante nos modernos estudos do pós-abolição: os projetos dos libertos, sua "visão" do que seria a liberdade, os significados deste conceito para a população que iria, finalmente, vivenciá-la, e não apenas para os que 0 definiram nos diferentes momentos do processo de emancipação. Em termos concretos, a liberdade al cançada com o fim legal da escravidão tevesignificados diferentes para ex-escravosurbanos erurais, com habilitações profissionais ou "deroça", homensou mulheres. Foi diferente para ex-escravos que, como na amaica, eram majoritariamente africanos ou filhos destes, em relação àqueles que, como nosEU A, eram a várias gerações nascidos em terras americanas, ou ainda em situações como Cuba e Brasil, nas quais as várias situações se misturavam. Foi diferente para populações que se acostumaram a misturar-se e a relacionar-se, por laços de vizinhança, compadrio, amizade ou casamento, a uma população livre pré-existente. Foi diferente para os que se viram livres em sociedades com forte construção legal relacionando igualdade e acesso à cidadania política, com presunção de plenos direitos a todos os cidadãos (desde quelivres e homens) ou em sociedades onde esta presunção não existia na prática, nas quais relações pessoais se faziam definidoras de direitos num quadro de manutenção de relações hierárquicas e clientelísticas, como a brasileira. 
N ecessariamente as expectativas concretas e projetos possíveis de inserção no mundo livre haveriam de sofrer diferenças conforme estas variáveis.

Apesar destas diferenças, muitos dos comportamentos e projetos das últimas gerações de escravos se mostraram semelhantes nas A méricas. D entre eles, destacam-se a busca general izada por mais autonomia e controle sobre tempo e ritmos de trabal ho, a busca da proteção dafamília com aluta(nem sempre vitoriosa) pela retirada das mulheres e crianças do trabal ho coletivo nas gangs ou "turmas", a recusa ao trabalho e as revoltas contra o tratamento quelhes lembrasse a escravidão, dentre eles restrições à mobilidade espacial e os castigos físicos. ${ }^{7}$

N o Brasil, o fim da escravidão e as reconfigurações sociais no pósabolição tiveram também contornos regionais específicos. A instituição praticamente se "dissolveu" no nordeste, terminando ali mais cedo do que no centro-sul. U m deslocamento maciço de escravos das regiões nordestinas, com destino principalmente ao sudeste, com base no tráfico interno, foi responsável por mudanças profundas nas duas regiões. N o sudeste, às vésperas da abolição, o vale do rio Paraíba, de ocupação mais antiga (início do século XIX), apresentava escravarias assentadas, com al gumas gerações deescravosjánascidas na região. Jánasáreas de ponta da cafeicultura paulista - que demandavam um crescente número de trabalhadores - disciplinar os recém chegados que vinham continuamente às fazendas que se abriam, mostrou-se mais problemático.

Ainda hoje, o processo de abolição da escravidão no Brasil foi bem mais estudado do ponto devista econômico e político do que de uma perspectiva social ou cultural. Enquanto problema econômico, quase naturalmentetendeu-sea privilegiar a questão da substituição do trabal ho nasáreas mais prósperas da cafeicultura paulista e a substituição quase absoluta do escravo negro pelo imigrante europeu. Aparentemente substituído pelo imigrante no 0 este Paulista e, em parte, também na cidade de São Paulo, tendeu-se a general izar a experiência paulista para o conjunto do país. Sintomaticamente, os primeiros estudos defôlego quetrataram do liberto após a emancipação, de uma perspectiva sócio-cultural, diziam respeito a São Paulo, desde o clássico de Florestan Fernandes aos trabal hos mais recentes de Reid Andrews e $\mathrm{M}$ aria $\mathrm{H}$ elena $\mathrm{M}$ achado. ${ }^{8}$ 
0 caso paulista, entretanto, não pode ser considerado isoladamente para se pensar a inserção social do liberto após a emancipação. 0 vertiginoso crescimento, tanto da lavoura cafeeira paulista quanto da cidade de São Paulo, após a abolição do cativeiro, demograficamente embasado na imigração subvencionada, subverteu muito rapidamente as relações de dependência entreex-senhores elibertos, permitindo, conformedesenvolve Andrews, que aqueles pudessem muito mais facilmente ignorar as reivindicações colocadas por estes. Além disto, apesar de contar com a terceira população escrava do país, o impacto demográfico da escravidão, especialmente no 0 este Paulista, não tem paralelo com o das antigas áreas escravistas do nordeste ou com o das regiões vizinhas, no Rio de Janeiro, em $M$ inas $G$ erais e em outras áreas da própria província de São Paulo.

N este artigo procuraremos trabalhar com alguns aspectos centrais já discerníveis das pesquisas sobre o período pós-abolição no Brasil, buscando enfatizar o papel jogado neste processo pelos últimos libertos epor suas expectativas e atitudes em relação à liberdade. $N$ ossa anál ise se concentrará, especialmente, no velho Vale do Paraíba, onde a escravidão enquanto instituição manteve atétardiamente sua vitalidade e a imigração estrangeira foi muito limitada. Buscamos, assim, contribuir parauma espéciede "química fina" deste processo, procurando cercar e problematizar aspectos do queentendemos como as principais demandas por inclusão, ou cidadania, perseguidas pelaúltima geração de escravos e por seusfilhos enetos. Entendemos que estas demandas se organizaram a partir de noções de direito peculiares a esta população que, obviamente, também mudaram ao longo do tempo. Indícios dos elementos que constituíram estas expectativas de direitos puderam ser percebidos através da documentação do registro civil, de notícias de jornais e da análise de processos criminais. Trabal hos recentes, que resultaram em dissertações e teses ainda não publicados reforçaram avalidadedeal gumasidéas quejá vínhamos discutindo econtribuíram decisivamente para os resultados deste ensai $0^{9}{ }^{9}$

Utilizamos também um outro tipo de fonte. São depoimentos de descendentes daúltima geração de escravos, ou de seus filhos, jábeneficiadospela lei do ventre livre. Em geral os netos desta geração. Sobre a utilização destes depoimentos, eo problema das fontes para uma abordagem histórica do pósabolição de modo geral, gostaríamos ainda de fazer alguns comentários. 


\section{0 pós-abolição e o problema das fontes}

Apesar de uma anteriormente propalada falta defontes, sabemos hoje que são inúmeras e ainda insuficientemente exploradas as fontes relativas à escravidão no Brasil, tendo em vista o estatuto jurídico específico que recaía sobre os escravos eque os tran sformava numa categoria classificatória necessária em quasequaisquer tipos defontes primárias do período. Q uando se trata do período pós-emancipação, entretanto, tem-se apenas (e mesmo assim precariamente) as designações de cor como via de acesso aos ex-cativos.

Estaéuma dificuldadegeral nas pesquisas sobrea experiência histórica pós-emancipação nas Américas. No Brasil, entretanto, é especialmente acentuada, não apenas pela inexistência de práticas legais, baseadas em distinções de cor e raça ou pela presença demograficamente expressiva, e mesmo majoritária, denegrose mestiços livres, antes da abolição, mas pelo desaparecimento, que se faz notar desde meados do século XIX, de se discriminar a cor doshomens livres nos registroshistóricos disponíveis. ${ }^{10}$ Processo cíveis e criminais, registros paroquiais de batismo, casamento eóbito, na maioria dos casos, não fazem menção da cor e, mesmo nos registros civis, instituídos em 1888, onde citar a cor era legalmente obrigatório, em muitos casos, ela se faz ausente.

Apesar da ênfase dautilização de classificações de cor no censo de 1890, - que denota as preocupações racialistas da quasetotal idade do pensamento social brasileiro do período, ${ }^{11}$ este recenseamento é considerado estatisticamente precário para qualquer análise demográfica minimamente confiável. D epois dele, o recenseamento de 1920 incorporaria o desaparecimento da cor às estratégias estatísticas do governo brasileiro, que só voltariam a se alterar com o censo de 1940.12

$N$ este contexto, a exploração de depoimentos orais de descendentes daúltima geração de escravos brasileiros, que começaram a ser produzidos deforma mais ou menos sistemática por diferentes pesquisadores desde 0 centenário da abolição, em 1988, ${ }^{13}$ apresentou-se como uma fonte alternativa para a abordagem histórica do período pós-emancipação. Entreestas iniciativas, desde 1994, o projeto M emórias do C ativer ro reuniu no LABH O IU FF diversos pesquisadores, num esforço de documentação epesquisa, que buscava conseguir produzir fontes de memória capazes de embasar uma 
abordagem histórica da inserção social do liberto após a abolição da escravidão. Esteacervo se constituiu fundamentalmentea partir do arquivamento no acervo do Laboratório das entrevistas produzidas pela pesquisa para a tese de doutorado de Ana M aria Lugão Rios, sobre a história da experiência familiar dos descendentes de libertos nas antigas áreas cafeeiras do Rio de Janeiro e de M inas G erais; para a tese de Robson Luís M achado M artins, desenvolvida em uma comunidade rural do Estado do Espírito Santo (município de Alegre), formada por descendentes de antigos escravos da região; al ém da produção de entrevistas diretamente pela equipe do LABH O I, sob a coordenação de $\mathrm{H}$ ebe $\mathrm{M}$ aria $\mathrm{M}$ attos. ${ }^{14}$

D e forma geral, escravidão e liberdade aparecem com diferentes significados nestes depoimentos. Significados que por vezes estavam referidosà abordagem do entrevistador, à história de vida do entrevistado ou ao contexto específico de cada entrevista. Para responder às perguntas dos entrevistadores, os entrevistadosfreqüentementerecorreram a contos populares ou ao que uma vez aprenderam nos livros didáticos, na igreja ou nos sindicatos, bem como às informações veiculadas sobre o tema pel o cinema e pela televisão. N este processo, o seriado americano Raízes (Roots), por exemplo, tornou-se referência recorrentedas respostas dosinformantes em algumas entrevistas realizadas em 1988.

Apesar disto, al guns padrões de referência à escravidão e ao processo de emancipação apresentaram-se incrivelmente similares nos diversosconjuntos de entrevistas analisadas permitindo identificar uma memória coletiva produzida no âmbito da tradição familiar dos descendentes dos últimos libertos, especialmenteno antigo sudestecafeeiro, ondemajoritariamente aqueles se concentravam.

A análise das fontes orais assim produzidas possibilitou não apenas complementar as lacunas das fontes escritas para 0 estudo das populações libertas. Elas abriram perspectivas de anál ise das várias formas possíveis de passagem da escravidão paraa liberdade. M ostram como, ainda sob a vigência daquela instituição, alguns marcos desta passagem (como a lei do ventrelivre, por exemplo) ficaram marcadas na memória familiar, apropriadas eressignificadas por seus descendentes ao longo do conturbado século XX.

A exploração sistemática de reminiscências do trabalho na infância, a construção de genealogias e a exploração de coincidências narrativas sobre 
o "tempo do cativeiro" foi a base comum do tratamento metodológico do nosso trabalho com as fontes orais para repensar o período pós-abolição. Especialmenteo uso degenealogias permitiu acompanhar verdadeiras sagas familiares que remontam ao início do século XIX e desdobram-se até as últimas décadas do século $X X .^{15}$

0 sresultados assim alcançados, associados com o conhecimento acumulado através da análise de fontes demográficas, cartorárias e judiciais, permitiram abordar aspectos do processo de inserção social dos últimos libertos após o fim do cativeiro que as abordagens exclusivamente baseadas em fontes escritas, atéentão, não haviam conseguido explorar. D entre estes aspectos, comecemos pelas opções quese abriram para os recém libertos sobre permanência, mobilidade em uma mesma região e migração, uma das primeiras decisões a serem tomadas.

\section{Mobilidade e migração no pós-abolição}

As discussões sobre mobilidade espacial têm ocupado posições de destaque nas abordagens historiográficas sobre o devir do mundo rural do sudeste escravista e pós-emancipação. ${ }^{16}$ Ainda antes da abolição uma das preocupações centrais dos senhores era a possibilidade dos escravos deixarem as fazendas nos quais foram cativos. D entre as estratégias senhoriais para evitar este abandono estava a de procurar ligá-los a si eàs fazendas por laços de gratidão, antecipando-se à abolição e concedendo alforrias em massa. A possibilidade de despertar-Ihes a gratidão ligava-se ao entendimento senhorial de que os escravos deveriam receber a liberdade de suas mãos, e não do Estado, e percebêla como uma dádiva senhorial. ${ }^{17}$

Esta estratégia, de eficácia bastante duvidosa, não era a única fonte de esperança de reter os libertos após o inevitável fim da escravidão. M uitos senhores percebiam que a mobilidade de parte significativa de seus escravos apresentava-se seriamente comprometida pelas próprias características das comunidades de escravos que habitavam suas senzal as. No Vale do Paraíba, boa parte dos escravos estava ligada entre si por extensas redes de parentesco, de por vezes até três gerações em uma mesma fazenda. 0 s provenientes do tráfico interno, parte dos quais foram adquiridos juntamente com suas famílias, encontraram nas novas fazendas oportunidades maio- 
res de constituir família e relações entre os escravos já residentes, do que encontrariam seus conterrâneos vendidos para as novas fazendas que se abriam nas áreas de expansão do café, como o chamado "oeste novo", na província de São Paulo. N as fazendas mais antigas, em geral, a relação homem/mulher era bem mais equilibrada que nas fazendas novas, as comunidades apresentavam-se mais estáveis, as rivalidades étnicas mostravamse em boa parte superadas, tornando-as um ambiente bem maisacolhedor do que o mundo essencialmente masculino e desenraizado das fazendas novas. ${ }^{18}$

Este momento na história das escravarias da região, de consolidação de parentelas e de superação de rivalidades ancestrais não passou despercebido pelos senhores mais argutos, queconsideravam, nas palavras do barão Luiz Peixoto de Lacerda Wernek, "impolítico" separarem-se escravos dehá muito acostumadosa viverem juntos. ${ }^{19}$ Senão pela gratidão, peloslaços que os escravos haviam construído entre si, que os amarravam a parentes idosose crianças, o abandono dasfazendas ou da região em quecresceram mostrou-se uma razão poderosa para fixar os libertos. Após um primeiro momento de intensa movimentação, inclusive com as passagens de trem subsidiadas pelo governo imperial, boa parte dos libertos considerou vantajosa a permanência na região em que já eram conhecidos e nas quais já contavam com uma rede de parentes e amigos.

Assim foi possível, nos anos de 1994 e 1995, encontrar pessoas como Seu Valdemiro, Seu Izaquiel, Seu Pedro M arin, D ona Zeferina, D ona Bernarda e muitos outros que viviam na mesma região, na mesma fazenda ou até na mesma casa em que seus avós, da primeira geração de libertos, viveram. Foi possível também encontrar remanescentes de antigas escravarias que permaneceram conformando comunidades de libertos de uma mesma fazenda, como as do Paiol, em Bias Fortes (M G) e a de São José, em Valença (RJ). ${ }^{20}$

D eixar ou não as fazendas onde conheceram o cativeiro foi uma decisão estratégica a ser tomada pel os últimos cativos após a abolição. 0 exercício da recém adquirida liberdade de movimentação teria que levar em conta as possibilidades de conseguir condições de sobrevivência que permitissem realizar outrosaspectos tão ou mais importantes da visão deliberdade dos últimos cativos, como as possibilidades de vida em família, mo- 
radia e produção doméstica, de maior controle sobre o tempo e ritmos de trabalho e, de modo geral, sobre as condições dos contratos a serem obtidos (de parceria, empreitada ou trabalho a jornada) tendo em vista as dificuldades então colocadas para o acesso direto ao uso da terra.

Estas condições, no imediato pós-abolição, apareceram como favoráveis aos libertos, em um momento de demanda por mão-de-obra e de fixação incipiente de normas de contrato de trabal ho no campo. A ilusão historiográfica da marginalização e "anomia" dos libertos se fez, em grande parte, porque a maioria deles conseguiu, em poucos anos, recursos sociais suficientes para não mais ser atingida pelo estigma da escravidão, seja negociando condições de trabal ho que privilegiavam a utilização do trabaIho familiar nas antigas fazendas ou nas novas áreas de expansão - contra as pretensões de manter uma organização coletivizada do trabal ho no eito dos últimos senhores - , ou ainda procurando situar-se como produtores independentes em áreas de subsistência. ${ }^{21}$

As condições favoráveis a esta capacidade de negociação dos libertos tinham, entretanto, como principal limite, exatamente a continuidade das identidades sociais, construídasainda durante o cativeiro; as distinções entre ex-senhores, libertos e homens nascidos livres, que os próprios libertos buscavam arduamente tornarem obsoletas.

N em só sua pressão agiu neste sentido. A República, ao queimar as matrículas de escravos eao promulgar uma C onstituição de cunho liberal, de certo modo contribuiu para que este processo de assimilação entre libertos e nascidos livres se efetivasse, mesmo que, num primeiro momento, ao reforçar o controle privado dos ex-senhores, em relação às instâncias públicas de repressão, tenha incentivado, em sentido oposto, a estratégia senhorial de se apoiar nos dependentes nascidos livres para forçar os libertos a continuarem onde sempre haviam estado. ${ }^{22}$

Sob a égide republicana, ainda, rapidamente se concluiu o processo de positivação das normas jurídicas relativas à propriedade da terra, revogando osúltimos vestígios de uma legislação que confundiafreqüentemente o legal com o costumeiro eque podia ser acionada a favor dos mais fracos, pelo menos se este tivesse um bom protetor. A lei Torrens, que atribuía aos Estados a tarefa de demarcar as terras devolutas, revelou-se mais eficaz que a Lei de Terras, que a precedeu, para declarar, como tais, terras ocupadas 
por situantes sem título de propriedade, retirando osúltimos resquícios de legitimidade deste tipo de ocupação. 0 s negócios e os espólios com situações (lavouras e benfeitorias) nos cartórios fluminenses, que decresciam desdea aprovação da Lei deTerras, simplesmente desaparecem, a partir da década de 1890. M esmo que ainda se "vendessem" informalmente lavouras, até mesmo em terras de meação, esta prática já não produzia nenhum título legal, a semel hança do que as pesqui sas com inventários post-mortem identificaram para o século XIX. Também o estabelecimento de impostos territoriais, em finais do século XIX, tanto no Rio de Janeiro quanto em $M$ inas $G$ erais, mesmo permanecendo aparentementeletra morta, do ponto de vista das rendas estaduais e do cerceamento do latifúndio, comprometeram a transmissão de herança das pequenas propriedades. ${ }^{23}$

Com o correr dos anos, portanto, a mobilidade passou de opção ou exercício de liberdade para uma espécie de maldição para os últimos libertos. Famílias como as da libertaT ibúrcia, sua filha C lotildee sua neta D ona $\mathrm{N}$ ininha, entre outras, tiveram nos constantes deslocamentos uma história de privações extremas e de desestruturação da vida familiar. ${ }^{24}$

M. Craton aponta como uma das características do pós-abolição no C aribea tendência das fazendas deaçúcar de manter um corpo permanente restrito e de recorrer a trabal hadores sazonais. Este corpo permanente, ainda segundo $C$ raton, seria composto pelos trabal hadores mais antigos e confiáveis esuasfamílias. ${ }^{25} \mathrm{O}$ mesmo parece ter acontecido em pelo menos parte do Vale do Paraíba, com um agravante. Com a cafeicultura em crise, muitos fazendeiros optaram pela criação extensiva de gado, atividade que exigiria ainda menos trabal hadores do que a manutenção das fazendas de café.

0 tempo viria cristalizar na região, para os libertos e seus filhos, duas possibilidades básicas, ou dois extremos polares em um continuum possível de situações. Por um lado, a estabilidade via contratos, no mais das vezes informais, que seriam social mente sedimentados com o passar do tempo e que aparecem, no discurso de filhos e netos destas famílias de camponeses negros, como degrande flexibilidade etol erância. Por outro, uma extrema mobilidadetanto para al guma famílias como para uma mai oria dehomens que, solteiros ou casados, iriam habitar os barracões das fazendas que abrigavam os trabalhadores sazonais. Para as famílias, uma trajetória vivida em casas precárias, emprestadas ou construídas por elas, na qual habitariam 
por um período limitado detempo. Algumas vezes este período foi tão limitado, que não puderam nem mesmo colher os frutos do que haviam plantado em suas roças. Já para os homens que migravam em busca de trabaIho, a habitação coletiva dos barracões ea comida fornecida pelas cozinhas das fazendas tinham ainda a agravante de contratos de trabal ho "a molhado", que reduziam substancial mente o salário se comparado com o salário "a seco", no qual o trabalhador recebia a comida de sua família. ${ }^{26}$

D entre a gama de entrevistas de filhos enetos de libertos, a alternativa de migração para as cidades, em especial para Juiz de Fora e para o Rio deJaneiro, mastambém para as pequenas cidades da região, aparece como forte alternativa para a geração dos depoentes ainda em sua juventude. $\mathrm{N}$ estes casos, pudemos detectar determinados padrões que aparecem recorrentemente a partir da década de 1930. Aurora, uma das netas mais vel has da liberta FranciscaX Xavier seguiu ainda adolescente, nosanos 1940, uma prima quejátrabal hava no serviço doméstico no Rio dejaneiro. Antes disto, 0 rmindo, irmão mais velho del zaquiel, tinha seguido para o cinturão rural de N ova I guaçu, a convite de um primo, para plantações de laranja na encosta dos morros e com acesso maisfácil aosmercados da cidade. N os anos 1930, também por motivos bastante fortes, seu Cornélio foge para ser aprendiz de padeiro, a primeira dentre uma série de ocupações urbanas, em Juiz de Fora. ${ }^{27}$

0 fato de a maior parte dos casos nos quais se detectou a migração para as cidades ter seguido a lógica do convite anterior por um parente, ou, especial mente nos casos das mul heres que saíram para se empregar no serviço doméstico, de famílias conhecidas na região de origem, não é uma novidadeem estudos sobremigração. 0 dado específico quecoloca o estudo desta migração, em particular, como um dos elementos da história do pósabolição é que ela se origina de um contexto criado tanto no processo de fixação das novas formas de trabalho no campo, quanto da ausência de políticas especificamentedestinadas a garantir al gum tipo deacesso à terra e ao crédito aos libertos e seus descendentes.

Voltando aos anos imediatamente após a abolição podemos detectar al guns outros elementos da experiência dos libertos que permaneceram no meio rural, dentreos quais al guns aspectos culturais, como a busca deregularizar formalmente suas relações familiares, de enfatizar o poder paterno e 
deconstruir uma imagem positiva enquanto trabal hador, traduzidana idéia de "boa reputação", estão entre os mais importantes.

\section{Casamento e família}

Em 1889, quando da instalação do registro civil de óbitos, nascimentos e casamentos em Paraíba do Sul (RJ), o cartório da antiga freguesia de C ebolas (atualmente Cartório de Inconfidência, terceiro distrito da cidade) admitiu procedimentosum tanto singulares nos registros, especialmente os de óbitos e de nascimentos. Ali, naquele ano, compareceu um pai para declarar o óbito de sua filha, que foi registrado assim:

Aos doze dias do mez de março do anno de mil oitocentos e oitenta enove, nesta parochia de Sant'Anna de C ebolas...compareceu em meu cartório José dos Santos Passos, natural da Bahia, residente nesta parochia, solteiro, jornaleiro, e perante as testemunhas abaixo nomeadas e assignadas declarou que no dia dez do corrente, no lugar denominado - Cordeiro - desta parochia, asseishoras datardefalleceu de dentição ecoqueluche, uma criança do sexo feminino, de cor preta, de nomeC ândida, de um anno etres mezes deidade, natural também desta parochia, filha natural de sua caseira denome Theodora M aria de Jesus, natural de Pernambuco... disendo maisele declarante que esta criança era também sua filha e como tal a reconhecia, e que tenciona casar-se com a dita sua caseira com a qual já tem mais dois filhos que são - Paulo, de sete annos, e M ercedes, de três annos (..... ${ }^{28}$

A informação requerida pelo registro, sobreo local, identidade, filiação e causa da morte de Cândida, foi cumprida. M as José foi além. N ão apenas reconheceu ali sua paternidade, como sua relação com a mãe da criança, os outros filhos que tinha com ela até o momento, suas idades e seu desejo de casar-se. Estas informações não eram requeridas pelo cartório, mas J osé e o escrivão acharam importante que constassem no documento.

D a mesma forma, no registro do nascimento de crianças negras e pardas, filhas de pais não casados, a intenção de casamento e o uso do cartório para registrar os outros filhos do casal foi uma constante. Em 1889, temos 230 crianças negras ou pardas registradas. D entre elas, $41 \%$ são legítimas, 21\% não tiveram o nome do pai registrado e $9 \%$ foram registradas por seus pais que reconheciam a relação que tinham com as mães dos pequenos, mas alguns escol heram expressar a ligação com as mães de for- 
ma diferente da de J osé quando se referiu aT heodora. Estes pais usaram, para designar as mães dos filhos que registravam como "uma mulher que vive em sua companhia" ou "uma mulher que está em sua companhia". Ambasas expressões, qualitativamente diferente de sua "caseira", que o D icionário de Vocábulos Brasileiros da época registrava como a mulher "que vive na casa de seu amante à laia de mulher legítima".

Além doscasosacima citados, o quemais chama a atenção para a nossa discussão, são as restantes 67 crianças (21\%) cujos pais também trouxeram para o escrivão informaçõesnão requeridas ou necessárias para o registro (videTabela 1). Estes pais não apenas reconheciam a paternidade como, a exemplo de José, expressavam a intenção de casar-se com a mãe das crianças, suas "caseiras", e ainda, conforme o caso, declaravam os outros filhos daquela união. Um exemplo é o de M anoel Ferreira J r., natural do C eará, jornaleiro, solteiro, que compareceu ao cartório em 23 defevereiro de 1889 para registrar o nascimento de sua filha I dalina Perpétua, tida com sua caseira Rachel Perpétua, reconhecer a paternidade da menina, declarar que tinha mais dois filhos daquela união, dar seus nomes e idades e expressar sua intenção de casar-se com Rachel. ${ }^{29}$

\section{Tabela 1: Situação conjugal dos pais de crianças pretas e pardas segundo o registro civil, em anos escolhidos, Cebolas, Paraíba do Sul (RJ)}

\begin{tabular}{|c|c|c|c|c|c|}
\hline Anos & Casados & Pretendem casar & $\begin{array}{c}\text { Reconhecem } \\
\text { a paternidade }\end{array}$ & Ausente & Total \\
\hline 1889 & 94 & 67 & 21 & 48 & 230 \\
\hline 1899 & 20 & 0 & 0 & 4 & 24 \\
\hline 1904 & 16 & 0 & 1 & 3 & 20 \\
\hline 1909 & 10 & 0 & 0 & 4 & 14 \\
\hline 1914 & 23 & 0 & 0 & 3 & 26 \\
\hline 1919 & 33 & 0 & 1 & 5 & 39 \\
\hline total & 196 & 67 & 23 & 67 & 353 \\
\hline
\end{tabular}

Fonte: Registro civil de nascimentos. Cartório de Inconfidência, segundo distrito de Paraíba do Sul (RJ). Livros número 1, 2, 5, 6, 7, 8, 9, 10 el1. 
0 novo serviço criado em C ebolas naquele ano estratégico, o seguinte ao da abolição, cumpria o papel que Ihe fora confiado. Criado ainda durante o Império, mas cujo alcance só se ampliaria no advento da República, pretendia que o registro dos atos vitais concernentes à vida da população fosse de responsabilidade do Estado. 0 ano de 1889 foi o mais procurado pelos pais de crianças negras para registrar nascimentos. Estas crianças responderam por $71 \%$ dos registros.

Em 1890, segundo o recenseamento, a população classificada como "preta" ou "parda" somava 57\% da população do município. Este dado, porém, não responde pela procura excepcional de pais de crianças negras pelo registro civil. A queda da procura foi acentuada nos anos seguintes. Ao longo do tempo, em uma mostra de cada cinco anos, tanto o número de crianças registradas, quanto a proporção de crianças negras, caiu drasticamente. Se em 1889 elas respondiam por $71 \%$ dos registros, em 1889 foram apenas $8 \%, 13 \%$ em 1904, sobem para 33\% em 1909 e 1914 e 43\% em 1919 (em 1894 a cor de nenhuma das 74 crianças foi registrada, e por isto 0 ano foi excluído da mostra, videTabela 2:

\section{Tabela 2: Porcentagem de registros de crianças pretas e pardas sobre o total de registros em anos escolhidos, Cebolas, Paraíba do Sul (RJ)}

\begin{tabular}{|c|c|c|c|}
\hline Anos & $\begin{array}{c}\text { \% de crianças } \\
\text { pretas e pardas }\end{array}$ & Total de registros & $\begin{array}{c}\text { \% de crianças } \\
\text { pretas e pardas }\end{array}$ \\
\hline 1889 & 230 & 323 & 71 \\
\hline 1899 & 24 & 310 & 8 \\
\hline 1904 & 20 & 156 & 13 \\
\hline 1909 & 14 & 45 & 33 \\
\hline 1914 & 26 & 78 & 33 \\
\hline 1919 & 39 & 90 & 43 \\
\hline total & 353 & 1020 & 34 \\
\hline
\end{tabular}

O bs: no ano de 1894 foram registradas 74 crianças. Em nenhum dos registros apareceu qualquer menção a cor das crianças. Por isto 0 ano foi excluído da mostra.

Fonte: Registro civil de nascimentos. Cartório de Inconfidência, segundo distrito de Paraíba do Sul (RJ). Livrosnúmero 1, 2, 5, 6, 7, 8, 9, 10 e 11. 
De um total de 679 nascimentos registrados, excluídos os de 1889, apenas 102 foram de crianças registradas como "pretas" ou "pardas". 0 registro tornou-se "branco" ou muitas vezes "sem cor" emuito menos procurado do que o fora em 1889. O utro dado importante é que também passou a atrair apenas uma parcela daqueles pais de crianças negras com situação civil já regular. A figura das caseiras, as promessas de casamento e as declarações incluindo os demais fil hos desapareceram. U ma regulamentação mais clara do que deveria ser registrado pode responder por esta ausência. M as os pais solteiros reconhecendo as crianças também evitaram o registro. N osanos cobertos pela mostra, apenas dois reconheceram a paternidade e dezenove crianças negras foram registradas sem que o nome do pai constasseno documento. A parcelamaissignificativa dapopulação depaisdecrianças negras que seguem procurando o registro civil é a de casados.

Estes dados tornam o ano de 1889 um ano muito especial para a análise das atitudes dos libertos que puderam ser percebidas no registro civil daquele cartório. A incerteza quanto às normas que regiam a produção do documento criou um escrivão receptivo às informações dos declarantes dos óbitos e nascimentos. M as o quefez os pais de crianças negras procurarem os cartórios naquele ano muito mais nos que nos seguintes foi uma motivação específica da conjuntura do pós-abolição. Foi a preocupação, claramente expressa, especialmente dos recém libertos, de regularizar e documentar suas situações familiares.

Sonia M aria de Souza nos mostra que nas vizinhanças do Vale do Paraíba (Juiz deFora) e em M inas G erais, esta preocupação foi registrada, por vezes com uma certa dose de ironia. Proclamas de casamentos delibertosforam publicadosem muitos periódicos, assim como notícias de casamentos em massa, como esta do D iário deM inas de 25 de setembro de 1888:

D esde 19 de maio a 17 do corrente, quatro mezes mais ou menos, casaramse em São João N epomuceno 250 libertos. Em Santa Bárbara, termo da mesma cidade, dizem queo número de casamentos de libertos subio a 300. 30

O s casamentos em massa são fortes indicadores da importância emprestada pel osúltimos cativos à legal ização formal de seus laços familiares. D efato, segundo os depoimentos de seus descendentes aqui considerados, seus avós ressaltavam como elementos constitutivos do tempo da liberda- 
de, a valorização de al guns elementos básicos ligados à moderna noção de direitos civis (o direito de "de ir e vir", o direito a constituir legalmente uma família e o direito à integridadefísica). A busca coletiva de legalizar as relações familiares constituídas ainda sob o cativeiro éum índice expressivo das expectativas formadas a partir dessa nova condição deliberdade. Esta atitude se ligava a uma preocupação ainda maior. A de construir uma imagem positiva da pessoa e da família como partede um conjunto devalores socialmentereconhecidos e reforçados, a que chamaremos de "reputação".

\section{Reputação}

Telemos I nácio, pai de Atílio I nácio e avô de Izaquiel Inácio, éprotagonista de uma história muito interessante que seu neto relatou em entrevista em 1994. Atílio teria participado da história efoi quem a repetiu para o filho. $\mathrm{N}$ ela, Telemos, um escravo, venceu uma turma de outros escravos colhendo mais café do quetodos eles em um dia de jornada detrabalho. A reputação de bom trabalhador teria sido o orgulho de seu senhor ea razão pela qual o fazendeiro se arriscou a apostar uma fazenda com outro senhor como seu precioso escravo Telemos, sozinho, era melhor trabalhador do que os outros em conjunto. N ão só a boa reputação deTelemos, mastambém a de Atílio, um liberto, é val orizada por seu Izaquiel. Para atestar a veracidade da história contada pelo pai ele diz:

Pois é, isso meu pai me falou e acredito que seja uma grande verdade, ele não era de mentir, um nada, não era de mentir, se ele falava alguma coisa aquilo era certo, sempre, graças a D eus, eleera um homem muito sério, para todo o lugar aqui em Parába elesfalam, "vocêéfilho do Atílio", então aquele era um homem sério... ${ }^{31}$

Ser filho de Atílio, no discurso de I zaquiel, aparece como um referendo de veracidade. Algo reconhecido pelas pessoas da cidade, mesmo aquelas que não o conheciam diretamente.

Em sua tese de doutorado, Sonia M aria de Souza cita um processo criminal de homicídio no qual uma das testemunhas da acusação, o liberto $M$ alaquias, denunciou o próprio irmão argumentando que o fez para que o nome de sua família não ficasse manchado. $N$ ão queria que toda a família fosse vista como criminosa. ${ }^{32}$ 
O s autos de processos de lesões corporais e de homicídios nos quais os libertos aparecem como réus e/ ou testemunhas em Juiz de Fora real çam a importância da reputação para a sentença final. U ma boa reputação, estabelecida dentro da própria comunidade liberta, foi freqüentemente garantia de credibilidade ou de penas mais leves. ${ }^{33}$

$\mathrm{N}$ as diversas entrevistas com descendentes destes últimos libertos, reunidas no acervo $\mathrm{M}$ emórias do C ativeiro, os pais ou avós dos narradores apareciam, na maioria dos casos, como I zaquiel I nácio, como escravos privilegiados, inseridos na comunidade escrava mais enraizada, com relações familiares complexas e relações específicas com os senhores, definindo-se como exceções nos quadros de violência próprios do tempo da escravidão. O s vizinhos, amigos e padrinhos que se reuniam para rezar o terço na casa dos pais de Valdemiro e Aurora, segundo se depreende de seu depoimento, emprestavam prestígio e influência a esta e outras famílias de libertos entrevistadas na região. Tornava-as importantes peças no jogo cotidiano da política e do trabalho. U m pequeno poder? Sim, pequeno, mas possível. Ao alcance dos libertos. Um elemento diferenciador para alguns na massa de ex-escravos que abriam seus caminhos no pós-abolição.

\section{Pátrio poder e integridade física}

As entrevistas consideradas, em muitos casos como os citados acima, nos falam de uma definição de cativeiro como ausência absoluta de direitos e de alternativas personalizadas de rompimento com esta condição, através da aquisição de direitos pessoais ou privilégios. $N$ este contexto, a libertação teria significado a transformação definitiva daqueles privilégios efetivamente em direitos. Para os homens, sobretudo, o direito de controlar o seu próprio corpo e de comandar o trabal ho da família.

Paulo Vicente M achado nasceu em 1910, filho caçula de Vicente $M$ achado, ex-cativo, que transformou seu nome em sobrenome de toda a família. Era trabalhador aposentado da Estrada de Ferro Leopoldina e morador em São G onçalo, no Estado do Rio, à época da entrevista. Vicente $M$ achado surgena entrevista dePaulo Vicente, concedidaaseu neto Robson M artins, em 1992 como o Velho Vicente, que contava histórias sobre "o tempo do cativeiro" ecomo o pai todo poderoso, que comandava a família 
e eventuais auxiliares nos serviços de roça. D ecidia também as mudanças dedomicílio e os casamentos dosfilhos. Paulo V icente secasou aos 15 anos, por ordem do pai, com D. Ana Cândida, filha de um sitiante vizinho, em Vala de Souza, lugarejo onde a família tornou-se proprietária de um pequeno sítio familiar, ainda nos anos de 1920. 0 s filhos abandonariam a propriedade paterna, ao longo dos anos 30 e 40.0 entrevistado não sabia precisar o destino do sítio após a morte dos pais. ${ }^{34}$

Segundo seu filho, Vicenteterianascido cativo em M inas G erais, onde citava especialmente a mãe e onde Paulo ainda conheceu um tio "valentão". Foi vendido como escravo que Vicente chegara à Fazenda da Presa, na divisa entre M inas G erais, o N orteFluminensee o Espírito Santo, onde então seexpandiaalavoura do café. A ser correto o depoimento, depreendese que Vicente não perdera o contato com a família em M inas, apesar da venda, ainda criança enas últimas décadas do cativeiro, para o Espírito Santo. Segundo Paulo Vicente, também D ona M ucolina U mbelina de Jesus, esposa deVicente, que "não alcançou o cativeiro", era natural deM inas G erais.

A parte mais rica do depoimento de Seu Paulo diz respeito a sua convivência direta com o pai, durante a infância, na Fazenda da Presa, eà adolescência, em Vala deSouza. Já se haviam passado mais devinte anos do 13 demaio, quando nasceu o menino Paulo, sétimo filho vivo do Velho Vicente e de $D$ ona M ucolina, meeiros de café na Fazenda da Presa. $N$ as lembranças do menino, todos os velhos da fazenda, brancos, pretos ou italianos (al guns dos mais velhos meeiros da fazenda o eram), pertenciam ao "tempo do cativeiro". Foi depois deste tempo que, segundo a narrativa de seu pai, os proprietários decidiram "dividir tudo" com o pessoal, engendrando a organização da fazenda em que nascera e da qual se lembrava.

Filho de um liberto, que trabal hava como meeiro na fazenda em que servira como cativo, a memória do trabalho, na infância de Seu Paulo, é marcada por um contexto sobretudo familiar. É a figura do pai que emerge também como patrão, dos filhos e eventuais jornaleiros. Era ele que "botava a gente" (afamília) e "botava os empregados" no serviço. N as palavras de Seu Paulo, "a lavoura era dele".

Esboça-se, assim, das memórias de Seu Paulo, que o funcionamento da Fazenda da Presa, na segunda década do século passado, se fazia baseado no trabal ho familiar de meeiros, recrutados inicialmente entrelibertos 
e imigrantes, onde o chefe da família controlava pessoal mente a organização da produção, inclusive a contratação de mão-de-obra remunerada auxiliar, nas épocas de colheita.

Tendo em vista a ênfase que a historiografia e a literatura antropológica tem dado ao papel da mulher, seja na família escrava, seja nas famílias "negras" dasfavelas ebairrospopulares das zonasurbanas do Brasil, de uma maneira geral o papel desta estrutura patriarcal no campesinato negro do centro-sul, quase diretamente formado pel os últimos cativos libertos pela Lei Áurea, em 13 de maio de 1888, propõeelementos para uma reavaliação tanto da literatura sobrefamília e relações de gênero nas comunidades escravas, quanto da experiência das comunidades negras nas cidades do centrosul, no processo de migração rural-urbano que caracterizou a história social da região durante este século.

Apesar disto, as famílias chefiadas por mulheres não eram incomuns, mesmo nas zonas rurais. E também para elas, é a defesa dos direitos civis básicos recém adquiridos que vão definir os principais aspectos e disputas imediatamente após a abolição do cativeiro. D ona N ininha, entrevistada em 1994, se disse neta da escrava Tibúrcia, e filha caçula de D. Clotilde. V ivia em Paraíba do Sul quando gravou histórias sobre sua avó e sua mãe. D entre as recordações da mãe, que faleceu em 1993, aos 94 anos, está uma frase que ela, ao que parece, gostava de repetir para justificar diversas atitudes. "M inha mãe foi escrava, eu não sou. E mamãefalava, vamosembora". Em al guns lugares, os irmãos de D. N ininha eram colocados para impedir que os passarinhos comessem a plantação de arroz, sob ameaça de surras. Segundo D . N ininha o proprietário "prometia bater, mas não me lembro se batia não. I sso não me lembro. M inha mãe falava assim 'no dia em que bater no meu filho, a gente vai embora'. I sto não impedia que a própria D . Clotilde batesse. Ela podia, mas mais ninguém." ${ }^{35}$

\section{A título de conclusão: os vários caminhos da cidadania e as visões de liberdade.}

Em resumo, um rápido balanço sobre a historiografia das sociedades pós-emancipação nas Américas, permite perceber que esta redefiniu, nos últimos anos, al guns dos conceitos chave para a abordagem da história do 
período. É comum percebermos nos textos sobreo assunto expressões que passaram a ganhar significado próprio. U ma delas e provavelmente a mais importante é a de "significados da liberdade" ou "visões da liberdade". A partir dessas expressões, os historiadores vêm tentando resgatar a agência social dos libertos na construção das sociedades pós-abolição, buscando perceber em que medida 0 evolver das sociedades que atravessaram este processo foi também moldado pelas ações dos próprios libertos.

A nosso ver, estefoi um passo fundamental para quepudéssemos colocar no palco os atores que faltavam. D este ponto de vista, o próximo e necessário passo desta discussão éainda uma questão em aberto. $N$ ão mais sobre as possíveis visões de liberdade geradas na escravidão. N ão mais sobre o cabo de guerra para a sobrevivência da plantation. 0 próximo passo lógico enecessário ésaber em quemedida este processo abriu uma rediscussão sobre pertencimento ou inclusão. Trata-se, fundamentalmente, dereconhecer queo processo de destruição da escravidão moderna estevevisceralmente imbricado com o processo de definição e extensão dos direitos de cidadania nos novos países que surgiam das antigas colônias escravistas. E que, por sua vez, a definiç̧ão e o al cance desses direitos esteve diretamente relacionado com uma contínua produção social de identidades, hierarquias e categorias raciais. D e fato, trata-se agora de recuperar a historicidade dos diferentes processos de desestruturação da ordem escravista e seus desdobramentos, seja no que se refere às relações de trabalho, às condições de acesso aos novos direitos civis e políticos para as populações libertas, de forma a conseguir historicizar também as formas de racialização das novas relações econômicas, políticas ou sociais.

Trata-se, portanto, de rever as clássicas relações entre escravidão, racialização e cidadania. Este último, um dos conceitos mais importantes do mundo contemporâneo e, por isto mesmo, um conceito perigoso de trabalhar historicamente. N ão basta defini-lo nos moldes do século XIX, que assistiu a maior parte dos processos defim da escravidão nas Américas. H á que redefini-lo respeitando as várias percepções que os atores históricos tiveram deste momento. A grande preocupação das elites contemporâneas aos processos de emanci pação era definir quem poderia ser cidadão. Enquanto historiadores, fomos atormentados por muito tempo sobrefantasias a respeito de "estoque racial", males ou benefícios da miscigenação 
etc... exatamente porque passamos muito tempo discutindo as visões das elites a respeito de cidadania, enão a dos "novos cidadãos", os ex-escravos. É exatamenteesta questão quea discussão sobreo pós-abolição nos permite estabelecer em uma nova perspectiva. Cidadania, na compreensão dos novos estudos sobreo pós-abolição, éum conceito essencialmentemutável, eapenas começamos a nos aproximar de uma história que dêconta desuas múltiplas facetas.

\section{Bibliografia}

ALM EID A, Fernanda M outtinho. E depois do Treze deM aio? Conflitos expectativas dos últimos libertos de Juiz de Fora (1888-1900). D issertação de mestrado. H istória, N iterói, U niversidade Federal Fluminense, 2003.

AN D REW S, George Reid. Blacks and whites in São Paulo, Brazil - 1888-1988. M adison: The University of Wisconsin Press, 1991.

AZEVED O , Célia M arinho. O nda negra, medo branco: o negro no imagi nário das elites. Rio de Janeiro: Paz eTerra, 1987.

BECKLES, H ilary \& SH EPHERD, Verene (ed.) C aribbean Freedom: society and economy from emancipation to thepresent. Kingston, Jamaica: Randle, Londres: 1993. BLACK BU RN , Robin. The O verthrow of Colonial Slavery, 1776-1848. Londres: Verso, 1988 (trad. Rio de Janeiro: Ed. Record, 2002).

BUTTLER, Karthleen M ary. The Economics of emancipation: Jamaica and Barbados, 1823-1843. Chapel Hill: University of N orth Carolina Press, 1995.

CALLARI, Cláudia Regina. I dentidade e cultura popular: histórias de vida de famíliasnegras. D issertação demestrado. H istória, UniversidadedeSão Paulo, 1993. CO O PER, F., H O LT, Thomas \& SC O TT, Rebecca. Beyond Slavery: explorations of race, labor and citizenship in postemancipation societies. $\mathrm{C}$ hapel $\mathrm{H}$ ill e Londres: The University of $\mathrm{N}$ orth Carolina Press, 2000.

COSTA, Emília V iotti da. D a senzala à colônia. Rio de Janeiro: DIFEL, 1966.

CRATO N, M ichael. Thetransition from slavery to freewagelabour in theC arebbean, 1789-1890: a survey with particular reference to recent scholarship, In: Slavery and Abolition, 13:2, 1992.

CROSS, Malcom \& HEU M AN, Gad (ed.). Labour in the Carebbean: from emancipation to independence. Londres: M acmillan, 1988. 
EISEM BERG , Peter. M odernização sem mudança: a indústria açucareira em Pernambuco, 1840-1910. Rio de Janeiro: Paz eTerra / Campinas: Unicamp, 1977. FARIA, Sheila de C astro. A colônia em movimento: fortuna e família no cotidiano colonial. Rio de Janeiro: N ova Fronteira, 1998.

FER N AN D ES, FLorestan. A integração do negro na soci edade de classes. São PauIo: Ática, 1978.

FERREIRA, M arieta de M oraes. Em busca da idade do ouro: as elites políticas fluminenses na Primeira República (1889-1930). Rio de Janeiro: UFRJ, 1994.

FLOREN TIN O, M anolo e JoséRoberto Góes. A paz nassenzalas: família escravas e tráfico atlântico, Rio de Janeiro, c.1790-c.1850. Rio de Janeiro: Civilização Brasileira, 1997.

FO N ER, Eric. N ada além da liberdade. Rio de Janeiro: Paz eTerra, 1988.

FRAG IN ALS, M anuel M., EN GERM AN, Stanley \& PO N S, Frank. Between slavery and freelabour: the Spanish C aribbean in the N ineteenth $C$ entury. Baltimore: John H opkins U niversity Press, 1985.

FRAGOSO, João e Ana M aria Rios. Um empresário brasileiro do oitocentos. In: M ATTOS, H ebe M aria \& SCH N O OR, Eduardo. Resgate - uma janela para 0 oitocentos. Rio de Janeiro: Top Books, 1995.

H IG M AN , B. W. ed. Trade, Government, and society in Caribbean history, 1700 1920. Kingston, Jamaica, W I: H einemann Educational Books, 1983.

H O LT, Thomas. The problem of freedom: race, labour and politics in Jamaica and Britain, 1832-1938. Baltimore: The Jinn H opkins U niversity Press, 1992.

JAN OTTI, M aria de Lourdes \& ROSA, Zita de Paula. M emory of Slaves in Black Family in São Paulo, Brazil. In: BERTAUX, D aniel \& THOM PSO N, Paul (ed.). Betwen generation: familymodels, myths, and memories O xford U niversity Press, 1993. KOWARICK, Lúcio. Trabalho e vadiagem: a origem do trabal ho livre no Brasil. São Paulo: Brasiliense, 1987.

M ACH AD O , M aria H elena. 0 plano e o pânico: os movimentos sociais na década da abolição. Rio de Janeiro: U FRJ/ED USP, 1994.

M AT TO S de C astro, H ebe M aria. Ao sul da história: lavradores pobres na crise do trabalho escravo. São Paulo: Brasiliense, 1987.

. D as cores do silêncio. Significados da liberdade no sudeste escravista. Rio de Janeiro: Arquivo N acional, 1995 / N ova fronteira, 1998. 
. \& SCH N O O R, Eduardo (O rgs.). Resgate- uma janela para o oi tocentos. Rio de Janeiro: Top Books, 1995.

. O s combates da memória. Escravidão e liberdade nos arquivos orais de des cendentes de escravos brasileiros. Tempo, v. III, n. 6.

M cG LYN , Frank \& D RESH ER, Seymour (ed.) TheM eaning of freedom: economics, politics, and culture after savery. Pittsburg: U niversity of Pittsburg Press, 1992.

RIO S, Ana M aria Lugão. Família e transição: famílias negras em Paraíba do Sul, 1870-1920. D issertação de mestrado. H istória. N iterói, U niversidade Federal Fluminense, 1990.

. M y mother was a slave, not mel Black peasantry and regional politics in Southeast Brazil. Tese de doutorado. H istória, U niversity of M innesota, nov. 2001. SCH WARCZ, Lilia M . 0 espetáculo das raças: cientistas, institui ções e questão racial no Brasil, 1870-1930. São Paulo: Companhia das Letras, 1993.

SC OTT, Rebecca. Slaveemancipation in Cuba: thetransition to freelabour, 16801899. Princeton: Princeton University Press, 1985.

SILVA, Eduardo. Barões e escravidão. Rio de Janeiro: N ova Fronteira, 1984.

SO U ZA, Sônia M aria de. Terra, família, solidariedade... Estratégi as de sobrevi vência camponesa no período detransi ção - Juiz de Fora (1870-1920). Tese de doutorado. H istória. N iterói: Universidade Federal Fluminense, 2003.

\section{Notas}

${ }^{1} \mathrm{~N}$ este sentido, cf., entre outros, CO STA, Emília V iotti da. D a senzala à colônia. Rio de Janeiro: DIFEL, 1966; KOWARICK, op. cit.; AZEVED O , Célia M arinho. O nda negra, medo branco: o negro no imaginário das elites. Rio de Janeiro: Paz e Terra, 1987 e LAM O U N IER, M aria Lúcia. D a escravidão ao trabalho livre. Petrópolis: Vozes, 1988.

${ }^{2} \mathrm{D}$ iversos textos foram consultados para traçar esta visão geral dos rumos da discussão do pós-emancipação, especialmenteno $C$ aribe, mas também nosEU A. D entreeles, destacamos principalmente os queapresentam, em parte ou no todo, uma abordagem comparativa: FO NER, Eric. Nada além da liberdade. Rio de Janeiro: Paz e Terra, 1988; FRAG IN ALS, M anuel M , EN GERM AN , Stanley \& PO N S, Frank. Between slavery and free labour: the Spanish Caribbean in the N ineteenth Century. Baltimore: John H opkins U niversity Press, 1985; SC OTT, R ebecca. Slave emancipation in Cuba: the transition to free labour, 1680-1899. Princeton: Princeton U niversity Press, 1985; H IG M AN , B. W. ed. Trade, Government, and society in Caribbean history, 1700-1920. Kingston: WI/ H einemann Educational Books, 1983; CRO SS, M alcom \& H EU M AN , G ad (ed.). Labour in the Carebbean: from emancipation to independence. London: M acmillan, 1988. Em 1992, 
M ichael CRAT O N publicou um ensaio no qual discute a historiografia sobre a transição para o trabalho livre no $\mathrm{C}$ aribe, com ênfase nos resultados dos debates da tese de Eric W illiams, intitulado "T he transition from slavery to free wage labour in the C aribbean, 1780-1890: a survey with particular referenceto recent scholarship", 1992. D esdeentão, outras obras de referência foram publicadas, entre elas: BUT TLER, Karthleen M ary. The Economic of emanci pation: Jamaica and Barbados, 1823-1843. C hapel H ill: University of N orth C arolina Press, 1995; BEC KLES, H ilary e Verene Shepherd (ed.). Caribbean Freedom: society and economy from emancipation to the present. Kingston, Jamaica: Randle, London, 1993; M CG LYN , Frank eD RESH ER, Seymour (ed.). The M eaning of freedom: economics, politics, and culture after slavery. Pittsburg: U niversity of Pittsburg Press, 1992; H O LT, T homas. The problem of freedom: race, labour and politics in Jamaica and Britain, 1832-1938. Baltimore: The Jihn H opkins U niversity Press, 1992 e, em especial, CO O PER, F., H O LT, Thomas \& SC OTT, Rebecca. Beyond Slavery: explorations of race, labor and citizen ship in postemancipation societies. Chapel $\mathrm{H}$ ill e Londres: The U niversity of $\mathrm{N}$ orth C arolina Press, 2000, cuja introdução levanta questões importantes para a conclusão deste artigo.

${ }^{3}$ Cf., especialmente, EISEM BERG, Peter. M odernização sem mudança: a indústria açucareira em Pernambuco, 1840-1910. Rio de aneiro: Paz eTerra, C ampinas, U nicamp, 1977 e M AT TOS de Castro, H ebe M aria. Ao sul da história: lavradores pobres na crise do trabalho escravo. São Paulo: Brasiliense, 1987.

${ }^{4} \mathrm{Cf}$. neste sentido, principalmente, $\mathrm{H} O \mathrm{LT}$, Thomas, op. cit.

${ }^{5}$ Cf. AN D REWS, G eorge Reid. Blacks and whites in São Paulo, Brazil - 1888-1988. M adison: The U niversity of W isconsin Press, 1991; M ACH AD O, M aria H elena. $O$ plano eo pânico. O smovimentos sociaisna década da abolição. Rio de Janeiro: U FRJ/ED U SP, 1994 eFRAG O SO , João \& RIO S, Ana M . L. U m empresário brasileiro nos oitocentos. In: M ATTOS, H ebeM . \& SCH N O O R, Eduardo. Resgate, uma janela para osoitocentos. Rio de Janeiro: Top Books, 1995.

${ }^{6}$ BLACKBURN, Robin. The O verthrow of Colonial Slavery, 1776-1848. Londres: Verso, 1988 (trad. Rio de Janeiro: Ed. Record, 2002).

${ }^{7}$ Sobre estas semel hanças, cf: H O LT, Thomas, op. cit.; M ACH AD O, M aria H elena, op. cit. e FO N ER, Eric, op. cit. Ver também M ATTOS, H ebe M aria. D as cores do silêncio. Significados da liberdade no sudeste escravista. Rio de Janeiro: Arquivo N acional, 1995/ N ova fronteira, 1998 e RIOS, Ana M aria Lugão. M y mother was a slave, not me! Black peasantry and regi onal politicsin Southeast B razil. Tese de doutorado. H istória, U niversity of M innesota, nov. 2001.

${ }^{8}$ FER N AN D ES, FL orestan. A integração do negro na soci edadede dasses. São Paulo: Ática, 1978; AN D REW S, G eorge Reid, op. cit. e M ACH AD O , M aria H elena, op. cit.

${ }^{9}$ Por exemplo, SO UZA, Sônia M aria de. Terra, família, solidariedade... estratégias de sobrevivência camponesa no período detransi ção - Juiz de Fora (1870-1920). Tese de doutorado. H istória. N iterói, U niversidade Federal Fluminense, 2003 eALM EID A, Fernanda M outtinho. E depois do Trezede M aio? Conflitose expectativasdosúltimoslibertosdeJ uiz de 
Fora (1888-1900). Dissertação de mestrado: H istória, N iterói, U niversidadeFederal Fluminense, 2003.

${ }^{10} \mathrm{Cf}$. M AT TOS, H ebe M aria, op. cit., capítulo 5, 1998.

${ }^{11}$ Cf. SCH WARCZ, Lilia M . 0 espetáculo das raças. cientistas, instituiçõese quetão racial no Brasil, 1870-1930. São Paulo: Companhia das Letras, 1993.

${ }^{12}$ Cf. AZEVED O, Aloysio Villela. O s recenseamentos no Brasil. Rio de Janeiro, 1990.

${ }^{13}$ D estacamoso projeto M emória da escravidão em famílias negras deSão Paulo, coordenado por M aria de Lourdes anotti eSueli Robles deQ ueirós, Centro de Apoio a Pesquisa Sérgio Buarque de H olanda, USP (caixas 1 a 16). Entre os trabal hos desenvolvidos pelos pesquisadores do projeto ver CALLARI, Cláudia Regina. I dentidadeecultura popular: his tórias de vida de famílias negras. D issertação de mestrado: H istória, Universidade de São Paulo, 1993 eJAN OT TI, M aria de Lourdes \& RO SA, Zita de Paula. M emory of Slavesin Black Familyin São Paulo, Brazil. In: BERTAUX, D aniel \& TH O M PSO N, Paul (ed.). Bewween generation: family modes, myths, and memories O xford U niversity Press, 1993.

${ }^{14}$ Laboratório de H istória $\mathrm{O}$ ral elmagem do programa de pós-graduação em história U FF (doravante LABH O I). Todas as entrevistas aqui mencionadas estão arquivadas nestelaboratório. Partedelas estão transcritasno sitedo LABH O I: www.historia.uff.br/labhoi, fazendo partedo acervo do projeto M emórias do C ativeiro (M C). M uitas das análi ises deste ensaio são retomadas de livro recém concluído a quatro mãos pel os autores deste artigo, com baseno trabalho conjunto no projeto $\mathrm{M}$ emórias do $\mathrm{C}$ ativeiro, com título provisório M emórias do Cativeiro: identidade, trabal ho ecidadaniano pós-abolição [C ivilização Brasileira, no prelo].

${ }^{15}$ Cf. RIO S, Ana M aria Lugão op. cit. 2001; M AT TOS, H ebe M aria. O s combates da memória. Escravidão eliberdade nos arquivos orais de descendentes de escravos brasileiros. Tempo, v. III, n. 6, pp. 119-138, 1998.

${ }^{16}$ FARIA, Sheila C astro. A colônia em movimento. Rio de Janeiro: N ova Fronteira, 1998; AZEVED O , Célia M arinho. 0 nda negra, medo branco: o negro no imaginário daselites. Século XIX. Rio de Janeiro: Paz eTerra, 1987 e M AT TO S. H ebe M aria, op. cit., capítulo 1, 1998. ${ }^{17}$ M AT TOS, H ebe M aria, op. cit., capítulos 1 e 12, 1998.

${ }^{18}$ Sobrea superação de rivalidades étnicas eo parentesco ver FLO REN TIN O , M anolo \& GÓ ES, José R. A paz nas senzalas. Famílias escravas e tráfico atlântico, Rio de Janeiro, c. 1790-c. 1850. Rio de aneiro: Civilização Brasileira, 1997. Sobre as características demográficas de fazendas antigas ver Rios, Ana M . L. Família e transi ção: famílias negras em Paraíba do Sul, 1870-1920. D issertação de mestrado. H istória. N iterói, Universidade Federal Fluminense, 1990.

${ }^{19}$ C arta do Barão de Paty do Alferes em 20 de Janeiro de 1858. Apud SI LVA, Eduardo, Barões e escravidão, p. 144, 1984.

${ }^{20}$ Entrevistas arquivadas no M C/LABH O I (M emória do Cativeiro/Laboratório de H istória 0 ral e Imagem, vide nota 12) sob os mesmos nomes referidos no texto.

${ }^{21}$ M AT TOS, H ebeM aria, op. cit., parte 4, 1998 e M AT TO S deC astro, H ebeM aria, op. cit., 1987. 
${ }^{22}$ FERREIRA, M arieta deM oraes. Em busca da I dadedo 0 uro: aselitespolíticasfluminenses na Primeira República, 1889-1930. Rio de Janeiro: UFRJ, 1994.

${ }^{23}$ M AT TOS, H ebe M aria, op. cit., cap. 19, 1998.

${ }^{24}$ D epoimento de Claudina ( $\mathrm{N}$ ininha), M C LABH O I.

${ }^{25}$ CRAT O N , M ichael, op. cit., 13:2.

${ }^{26}$ A discussão sobre estabilidade/mobilidade e contratos no pós-abolição está em RIOS, Ana M aria Lugão, op. cit; 2001.

${ }^{27}$ Entrevistas dos irmãos Aurora, Valdomiro e H elena, de I zaquiel Inácio e de C ornélio, $\mathrm{MC} / \mathrm{LABHO}$.

${ }^{28} \mathrm{C}$ artório de Inconfidência, (segundo distrito de Paraíba do Sul, Rio deJ aneiro), registro de óbitos, Livro 1, Termo 44.

${ }^{29}$ Cartório de Inconfidência, registro de nascimentos, Livro 1, Termo 23.

${ }^{30}$ SO UZA, Sônia M aria de, op. cit., p. 259, 2003.

${ }^{31}$ Entrevista de Izaquiel Inácio, M C/LABH O I.

32 SO UZA, Sônia M aria de, op. cit., p. 276 e seguintes, 2003.

${ }^{33} \mathrm{Cf}$. os processos de lesões corporais apresentados por ALM EID A, Fernanda M outtinho, op. cit., 2003 e os processos criminais em SO U ZA, Sônia M aria de, op. cit., 2003.

${ }^{34}$ Entrevista de Paulo V icente $M$ achado, M C/LABH O I. Esta análise retoma com pequenas modificações a abordagem desta entrevista em M AT TO S, H ebe M aria, op. cit., capítulo 19, 1998.

${ }^{35}$ Entrevista de N ininha (Claudina de Souza), M C/LABH OI.

\section{Resumo}

0 artigo discute as variáveis mais importantes nos processos de pós-abolição nas Américas, dando destaque as expectativas alimentadas pela última geração de escravos e suas atitudes nas primeiras décadas após o fim da escravidão. Procura inserir o caso brasileiro e sua especificidade e se detém na análise das atitudes dos libertos do sudeste no sentido de proteger a família, estabelecer uma "boa reputação", exercer o pátrio poder eval orizar aspectos importantes da cidadania. U tiliza diversas fontes, principalmente o registro civil, jornais e depoimentos de netos de escravos. Palavras-chave: pós-abolição; família; cidadania

\section{Abstract}

The article discuss important variables on post-abolition literature, stressing the expectations and attitudes of the slaves' last generation in 
the first decades after theend of slavery. It al so focuses the Brazilian specific features, analyzing freed people willingness to protect family, to establish a "good reputation", to exercise rights of fatherhood and to enhance important aspects of citizenship. It uses several primary sources, specially birth records, newspapers and testimonies of slaves grandchildren. Key-words: post emancipation; family; citzenship 